\title{
Mermer ve Seramik Malzemelerinin FRP ile Güçlendirilmesi
}

\author{
${ }^{1 *}$ Ferhat Aydın ve ${ }^{2}$ Ali Sarıbıyı \\ ${ }^{1,2}$ Sakarya Uygulamalı Bilimler Üniversitesi, Teknoloji Fakültesi, İnşaat Mühendisliği Bölümü, Türkiye
}

\section{Özet}

Mermer ve seramik malzemelerin kullanım amaçları gereği geniş yüzeyli ve ince cidarlı üretilmeleri gerekmektedir. İnce üretilmeleri nedeniyle taşıma ve montaj esnasında kırılma riski altındadır. Belirtilen risklerden dolayı üreticiler bu tür malzemelere sıvı kimyasal emdirerek veya alt yüzeylerine eğilme etkisinde çekme dayanımı yüksek malzemeler yapıştırarak çözümler sunmaktadır. Bu çalışmada yapı endüstrisinde yoğun şekilde kullanılan mermer ve seramik yapı malzemelerine çeşitli güçlendirme yöntemleri uygulanmış ve eğilme performansları incelenmiştir. Güçlendirme yapılmamış referans numunelere göre Fiber Takviyeli Plastik (FRP) ve polipropilen fitiller ile güçlendirilen numunelerin eğilme davranışları deneysel olarak araştırılmıştır. Epoksi ile malzeme alt yüzeylerine FRP ve fitil yapıştırılarak, malzeme davranışları karşılaştırılmıştır. Her iki malzeme türü için de lifli güçlendirmenin dayanımını büyük oranlarda artırdığı ve güçlendirme tekniğinin çok önemli bir etken olduğu belirlenmiştir.

Anahtar Kelimeler: Mermer, seramik, FRP, güçlendirme, lif

\section{Strengthening with FRP of Marble and Ceramic Materials}

\begin{abstract}
Marble and ceramic materials should be produced with wide surfaces and thin walls due to their intended use. They are at risk of fracture during transportation and assembly due to their fine production. Due to the mentioned risks, manufacturers offer solutions by absorbing liquid chemicals to such materials or by applying high tensile strength materials under bending to their lower surfaces. In this study, various reinforcement methods have been applied to marble and ceramic building materials which are used extensively in the building industry and their flexural performances have been investigated. The flexural behaviour of samples reinforced with Fiber Reinforced Plastic (FRP) and polypropylene suppositories was investigated experimentally. FRP and polypropylene were bonded to the lower surfaces of the samples using epoxy and the material behavior was compared. For both types of materials, it was determined that the strengthening of the fibrous reinforcement greatly increased the strength and strengthening technique was a very important factor.
\end{abstract}

Key words: Marble, ceramic, FRP, strengthening, fiber

\section{Giriş}

Mermer ve seramik malzemeler ince cidarlı ve geniş yüzeye sahip olduklarından çekme kuvveti etkisinde düşük yüklerde kırılabilmektedir. Genellikle gevrek yapıya sahip bu malzemeler ani olarak kırılmakta olup tokluk ve eğilme dayanımları düşüktür. Üreticiler bu tür yapı

*Corresponding author: Address: Sakarya Uygulamalı Bilimler Üniversitesi, Teknoloji Fakültesi, İnşaat Mühendisliği Bölümü, Esentepe Kampüsü, Sakarya, Türkiye. E-mail address: ferhata@sakarya.edu.tr, Phone: +902642956475321 
malzemelerinde belirtilen etkilere karşı malzeme alt yüzeyine plastik fitil yapıştırarak eğilme performansını artırmaya çalışılmaktadır. Bunun dışında malzeme üreticileri mermerlere akıcı kıvamda dolgu malzemesi emdirilmesi yöntemi [1,2] ile güçlendirme yapmaktadırlar.

Mermer ile yapılan güçlendirme çalışmaları incelendiğinde Liu ve arkadaşları [3] çalışmalarında FRP atıklarını ve doymamış polyester reçine yapay mermer yapı elemanlarında kullanılmışlardır. FRP üretimi yapan testislerde ortaya çıkan cam elyaf takviyeli plastik atığı birçok çevre sorununa neden olmaktadır. Çalışmalarında doymamış polyester reçine esaslı yapay mermeri zenginleştirmek için GFRP atığı eklenmiştir. FRP atık içeriğinin ve partikül büyüklüğünün yapay mermerin mekanik özellikleri üzerindeki etkileri tartışılmıştır. Sonuçlar, FRP atık içeriğinin ve partikül boyutunun yapay mermerin mekanik özellikleri ile yakından ilişkili olduğunu göstermiştir. Test sonuçları incelendiğinde eğilme dauanımı 23.72 MPa, basınç dayanımı 79.13 MPa bulunmuş ve kullanılan partikülün boyutuna göre FRP atığı bulunmayan suni mermerlerin dayanımına göre \%75.8 ve \%128.1 artmıştır. Diğer bir çalışmada [4] FRP atıklarının epoksi esaslı yapay granitin özellikleri üzerindeki etkisini incelemişlerdir. Epoksi reçinesi, FRP artığı, granit ve dolgu maddeleri üzerinde yapılan çalışmada, FRP artığı ve epoksi esaslı yapay granitlerin farklı oranlarda hazırlanmıştır. Normal basınç ve sıcaklık altında kalıplama yapılarak hazırlanmış, yapay granitlerin eğilme ve basınç dayanımı incelenmiştir. SEM, yapay granitlerin iç mikro yapısını gözlemlemek için kullanılmıştır. Zhu ve arkadaşları [5] çeşitli nem ortamında CFRP ile güçlendirilmiş mermer eğilme kapasitesini test etmişlerdir. Çalışmada üç grupta toplam dokuz mermerin eğilme testi yapılmıştır. Test sonuçları karşılaştırılmış ve CFRP takviyeli mermerin eğilme kapasitesini arttırmak için araştırma yapılmıştır. Test sonucu, mermerin taşıma kapasitesinin çeşitli ortamlardan etkilenmediğini ve CFRP ile takviye edilen mermerin eğilme kapasitesinin büyük ölçüde artabileceğini belirtmişlerdir. Bellinia ve arkadaşları [6] hem ağırlı̆̆ını düşürmek hem de mekanik dayanımlarını artırmak amacıyla mermer ve granit numuneler kullanılarak sandviç lamine yapı elemanları oluşturmuşlar ve eğilme testleri yapmışlardır. Granit ve mermer kiriş elemanların alt yüzeyine yüksek dayanımlı epoksi-cam laminantlar yapıştırarak test etmişlerdir. Her numune türü için büyük oranlarda dayanım artışlarının olduğunu belirtmişlerdir. Yap1 malzemelerinin FRP ile güçlendirilmesi yöntemi son yıllarda birçok araştırmacı tarafından yoğun bir şekilde incelenmektedir. Özelikle betonarme yapı elemanların FRP kumaşlar ile güçlendirilmesi [7-9], çelik yapı elemanların FRP lamine ile güçlendirilmesi [1011] ve ahşap yap1 elemanların FRP malzeme ile güçlendirilmesi [12-14] sıkça görülen uygulamalardır. Bu çalışmada yapılan çalışmalardan farklı olarak mermer ve seramik olmak üzere iki tür malzeme kullanılarak FRP lifler ve polipropilen lifler ile güçlendirme yapılarak referans numunelere göre dayanım ve tokluk açısından karşılaştırılmıştır.

\section{Malzeme ve Metot}

Deneysel çalışmalarda seramik ve mermer olmak üzere iki tür malzeme kullanılmıştır. Her numune türünden 5'er adet olmak üzere, güçlendirme malzemesi olarak cam lifli örgü ve polipropilen fitil kullanılmış (Tablo 1), eğilme testleri yapılarak referans numunelere göre güçlendirilmiş numunelerin performans artışları incelenmiştir. Mermer deneylerinde referans, fabrikada üretilmiş polipropilen fitilli, laboratuvarda üretilmiş polipropilen fitilli ve cam lifli olmak üzere 4 tür, 
seramik deneylerinde ise referans, polipropilen fitilli ve cam lifli olmak üzere 3 tür numune kullanılmıştır.

Tablo 1. Numune tür ve adetleri

\begin{tabular}{|c|c|c|}
\hline & Mermer & Seramik \\
\hline Referans & 5 & 5 \\
\hline Cam Lifli & 5 & 5 \\
\hline Polipropilen & 5 & 5 \\
\hline Polipropilen Fitilli (Fabrika) & 5 & - \\
\hline
\end{tabular}

Deneylerde kullanılan mermer numuneleri 400x100x20 mm boyularında, 20 adet olmak üzere fabrikadan temin edilmiştir. Belirtilen mermerler $300 \mathrm{~mm}$ mesnet açıklığında üç noktalı eğilme testine tabi tutulmuştur. Seramik numuneler ise $200 \times 100 \times 5 \mathrm{~mm}$ boyularında toplam 15 adet olmak üzere $150 \mathrm{~mm}$ mesnet açıklığında eğilme testi yapılmıştır. Mermer ve seramik numunelerin güçlendirme işlemleri Şekil 1'de ve eğilme testleri Şekil 2'de görülmektedir.

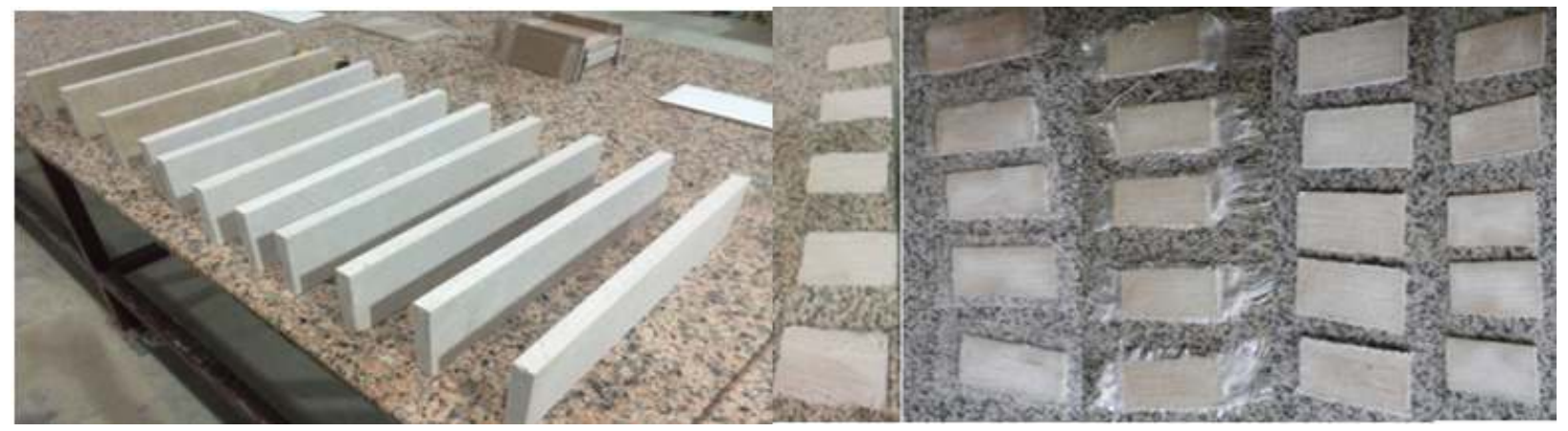

Şekil 1. Mermer ve seramik numunelerin hazırlanması

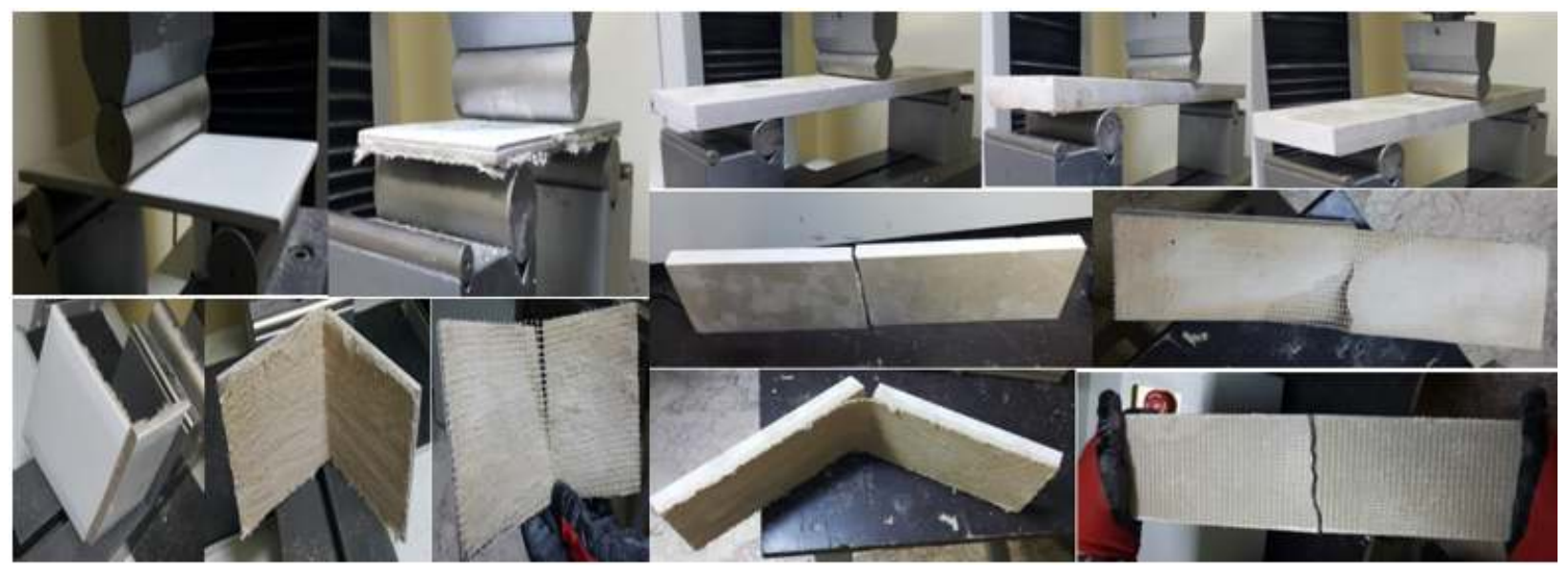

Şekil 2. Mermer ve Seramik eğilme testleri

Mermer ve seramik gibi malzemelerin çekme dayanımının düşük ve gevrek malzeme olmalarından dolayı bu malzemelerin çekme etkilerine karşı performansını artırmak amacıyla FRP cam lifler ile güçlendirilmiştir. Cam lifli malzeme ile birlikte üreticilerin kullandığı polipropilen fitil deney 
numunelerinin alt yüzeylerine epoksi ile yapıştırılarak test edilmiştir. Yapılan deneysel çalışmalarda kullanılan güçlendirme malzemelerinin teknik özelikleri Tablo 2'de verilmiştir.

Tablo 2. Malzemelerin Özelikleri

\begin{tabular}{lcc}
\hline & Cam Lifli Kumaş & Polipropilen Filtil \\
\hline Çekme Dayanımı & $3500 \mathrm{MPa}$ & $30 \mathrm{MPa}$ \\
\hline Özgül Ağırlık & $2.55 \mathrm{gr} / \mathrm{cm}^{3}$ & $0.92 \mathrm{gr} / \mathrm{cm}^{3}$ \\
\hline Elastisite Modülü & $75 \mathrm{GPa}$ & $1,1 \mathrm{GPa}$
\end{tabular}

\section{Deney Sonuçları}

\subsection{Mermer Numunelerin Test Sonuçları}

Yapılan 3 noktalı eğilme testeri neticesinde mermer numunelere ait yük-sehim grafikleri oluşturulmuş ve eğilme dayanımları hesaplanmıştır. Referans numunelerden başlamak üzere güçlendirilmiş mermer numunelerin eğilme grafikleri Şekil 3-6'da verilmiştir.

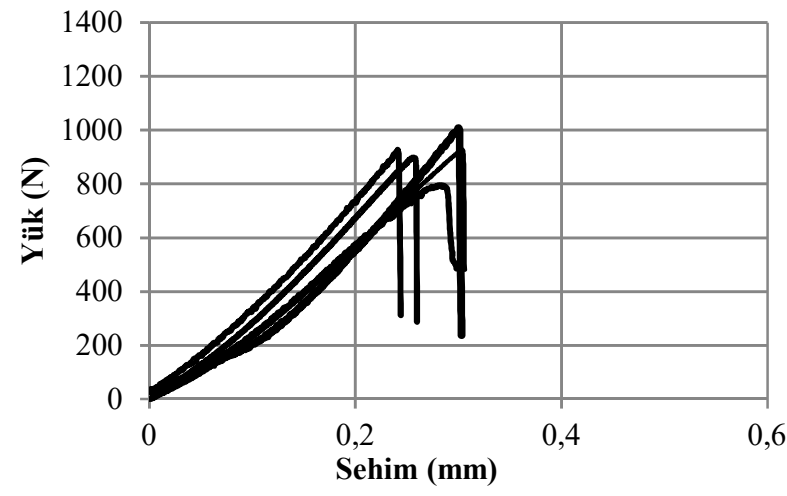

Şekil 3. Referans mermer yük-sehim grafikleri

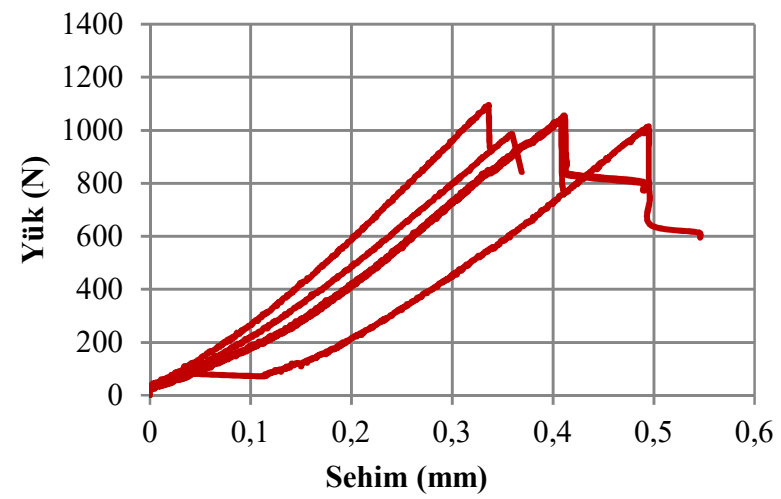

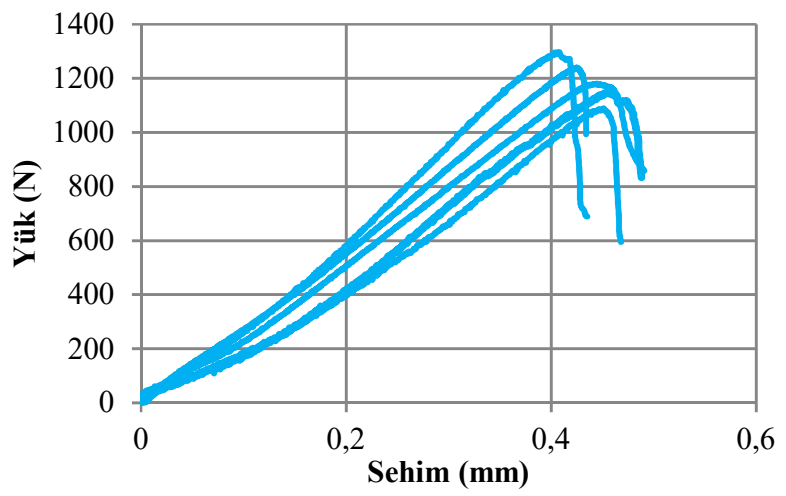

Şekil 4. Cam lifli mermer yük-sehim grafikleri

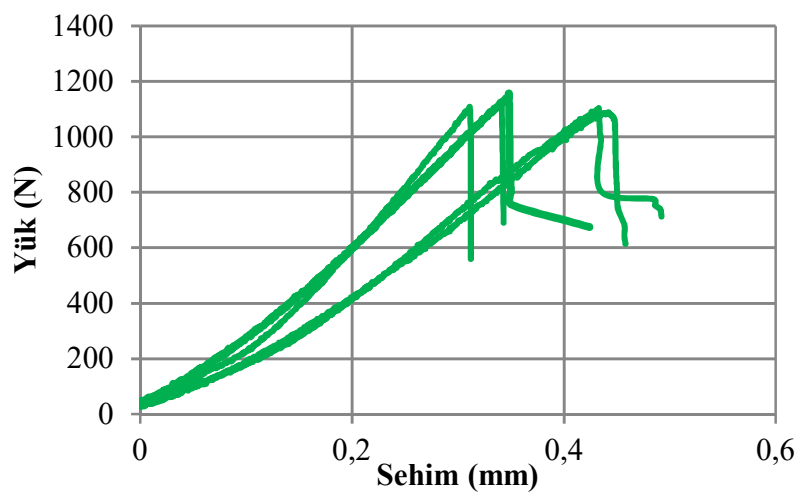

Şekil 5. Fileli mermer yük-sehim grafikleri (Fabrika) Şekil 6. Fileli mermer yük-sehim grafikleri (Laboratuvar) 
Test sonuçlarından elde edilen yük, hesaplanan eğilme dayanımları, kırılma toklukları, ve standart sapma değerleri Tablo 3'de verilmiştir. Her numune türünü temsil eden yük-sehim grafikleri tek grafik üzerinde karşılaştırılarak Şekil 7'de görülmektedir. Eğilme dayanım ortalamaları ve kırılma tokluklarının karşılaştırması ise Şekil 8'de verilmiştir.

Tablo 3. Mermer eğilme test sonuçları

\begin{tabular}{|c|c|c|c|c|c|c|c|c|}
\hline $\begin{array}{l}\text { Numune } \\
\text { Türü }\end{array}$ & $\begin{array}{c}\mathrm{N} \\
\mathrm{O}\end{array}$ & $\begin{array}{l}\text { Yük } \\
(\mathrm{N})\end{array}$ & $\begin{array}{l}\text { Eğilme } \\
\text { Dayanımı } \\
\left(\mathrm{N} / \mathrm{mm}^{2}\right)\end{array}$ & $\begin{array}{l}\text { Standart } \\
\text { Sapma } \\
\left(\mathrm{N} / \mathrm{mm}^{2}\right)\end{array}$ & $\begin{array}{c}\text { Ortalama Eğilme } \\
\text { Dayanımı } \\
\left(\mathrm{N} / \mathrm{mm}^{2}\right)\end{array}$ & $\begin{array}{l}\text { Kırılma } \\
\text { Tokluğu } \\
(\mathrm{Nmm})\end{array}$ & $\begin{array}{l}\text { Standart } \\
\text { Sapma } \\
(\mathrm{Nmm})\end{array}$ & $\begin{array}{c}\text { Ortalama Kirılma } \\
\text { Tokluğu } \\
(\mathrm{Nmm})\end{array}$ \\
\hline \multirow{5}{*}{$\begin{array}{l}\text { Mermer } \\
\text { Referans }\end{array}$} & 1 & 1007 & 11.33 & \multirow{5}{*}{0.86} & \multirow{5}{*}{10.23} & 302.1 & \multirow{5}{*}{35.23} & \multirow{5}{*}{252.28} \\
\hline & 2 & 926 & 10.42 & & & 276.9 & & \\
\hline & 3 & 795 & 8.94 & & & 228.2 & & \\
\hline & 4 & 920 & 10.35 & & & 223.3 & & \\
\hline & 5 & 897 & 10.09 & & & 230.9 & & \\
\hline \multirow{5}{*}{$\begin{array}{l}\text { Mermer } \\
\text { Cam } \\
\text { Lifli }\end{array}$} & 1 & 1296 & 14.58 & \multirow{5}{*}{0.90} & \multirow{5}{*}{13.38} & 525.7 & \multirow{5}{*}{26.29} & \multirow{5}{*}{524.48} \\
\hline & 2 & 1089 & 12.25 & & & 485.1 & & \\
\hline & 3 & 1148 & 12.92 & & & 533.1 & & \\
\hline & 4 & 1176 & 13.23 & & & 558.8 & & \\
\hline & 5 & 1237 & 13.91 & & & 519.7 & & \\
\hline \multirow{5}{*}{$\begin{array}{l}\text { Mermer } \\
\text { Fabrika } \\
\text { Fileli }\end{array}$} & 1 & 1095 & 12.32 & \multirow{5}{*}{0.48} & \multirow{5}{*}{11.65} & 367.5 & \multirow{5}{*}{34.69} & \multirow{5}{*}{397.9} \\
\hline & 2 & 985 & 11.08 & & & 353.6 & & \\
\hline & 3 & 1040 & 11.70 & & & 424.3 & & \\
\hline & 4 & 1006 & 11.31 & & & 416.4 & & \\
\hline & 5 & 1051 & 11.82 & & & 427.7 & & \\
\hline \multirow{5}{*}{$\begin{array}{c}\text { Mermer } \\
\text { Laboratuvar } \\
\text { Fileli }\end{array}$} & 1 & 1103 & 12.41 & \multirow{5}{*}{0.30} & \multirow{5}{*}{12.55} & 475.6 & \multirow{5}{*}{68.64} & \multirow{5}{*}{407.74} \\
\hline & 2 & 1156 & 13.01 & & & 402.3 & & \\
\hline & 3 & 1125 & 12.66 & & & 341.8 & & \\
\hline & 4 & 1107 & 12.45 & & & 339.3 & & \\
\hline & 5 & 1085 & 12.21 & & & 479.7 & & \\
\hline
\end{tabular}

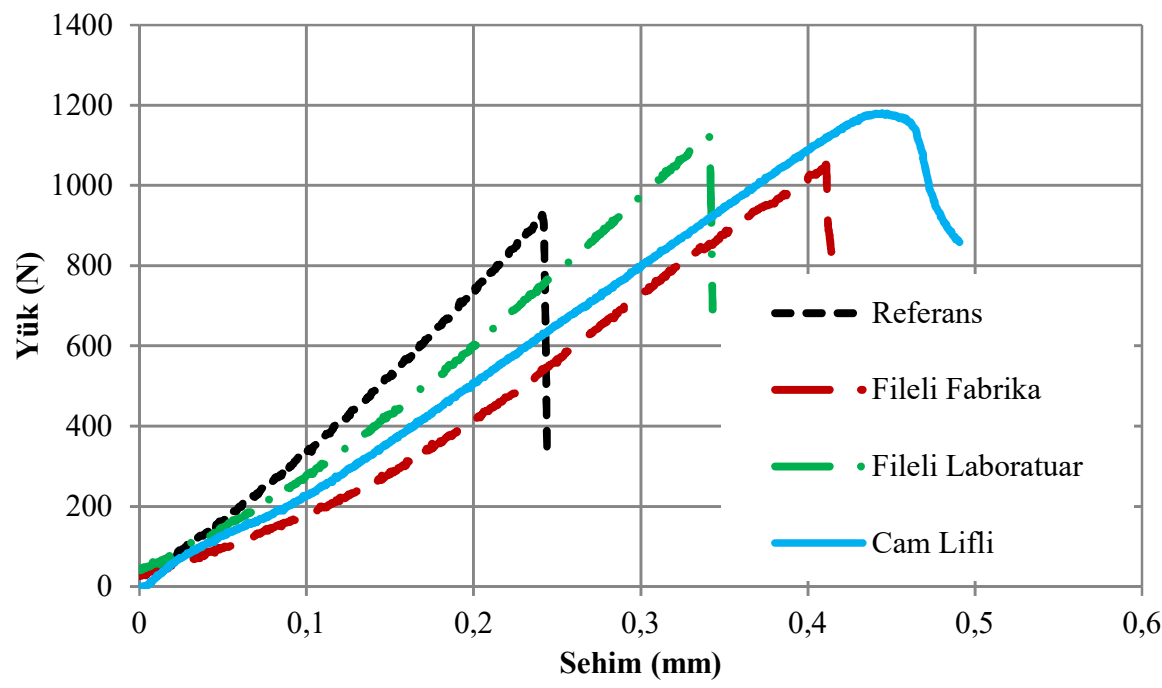

Şekil 7. Mermer yük-sehim grafikleri karşılaştırma 

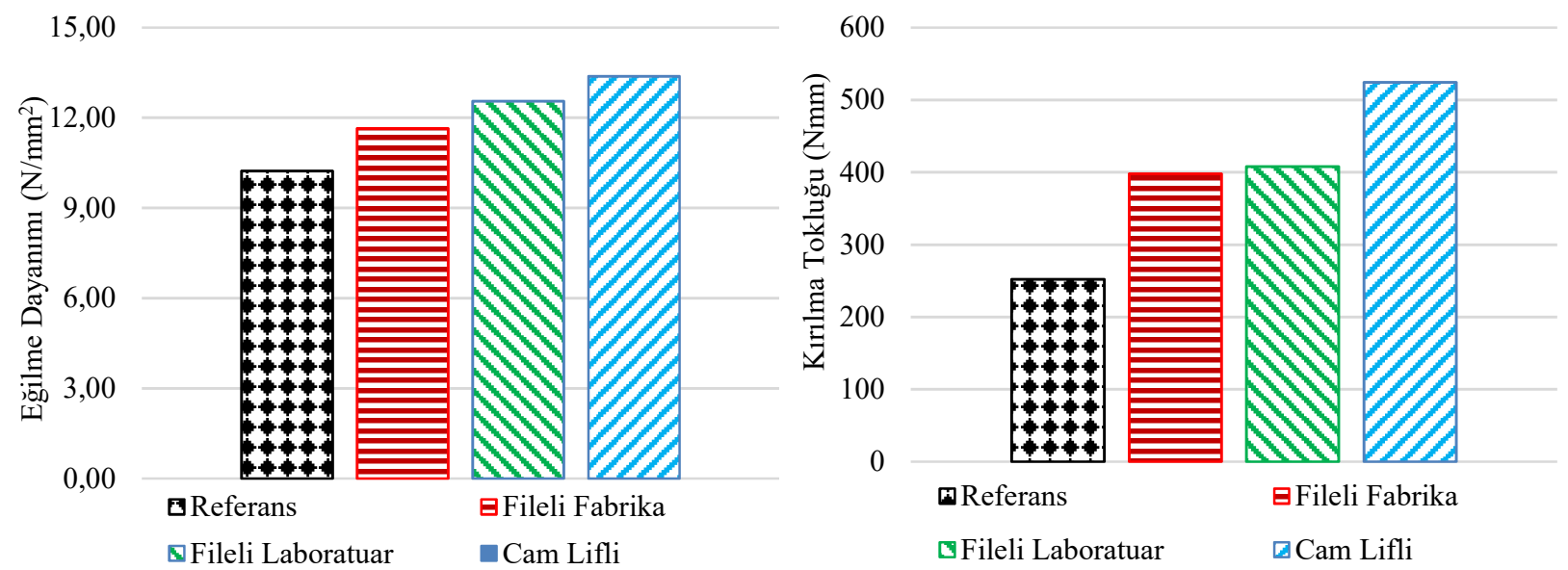

Şekil 8. Mermer numunelerin eğilme dayanımı ve kırılma tokluğu karşılaştırması

Deney sonuçları incelendiğinde referans mermer numunelerine göre eğilme dayanımları fileli fabrika üretimi numunelerde $\% 13.8$, fileli laboratuarda üretilen numunelerde $\% 22.7$ ve cam lifli mermer numunelerinde $\% 30.8$ oranında artttığı belirlenmiştir. Kırılma tokluğu referans numune sonuçlarına göre fileli fabrika üretimi numunelerde $\% 58$, fileli laboratuarda üretilen numunelerde $\% 62$ ve cam lifli mermer numunelerinde $\% 108$ oranında artmıştır. Cam lif ve fitil ile güçlendirilmiş numuneler karşılaştırıldığında ise cam lifli güçlendirme fabrika fitilli numunelere göre eğilme dayanımı $\% 15$, kırılma tokluğu $\% 32$ oranında ve laboratuar fitilli numunelere göre $\% 6$, kırılma tokluğu \%28.4 oranında arttığı tespit edilmiştir.

\subsection{Seramik Numunelerin Test Sonuçları}

Seramik numuneler ile yapılan eğilme testeri neticesinde yük-sehim grafikleri Şekil 9-12'de. eğilme dayanımları, kırılma toklukları ve standart sapma değerleri Tablo 4 'te verilmiştir.

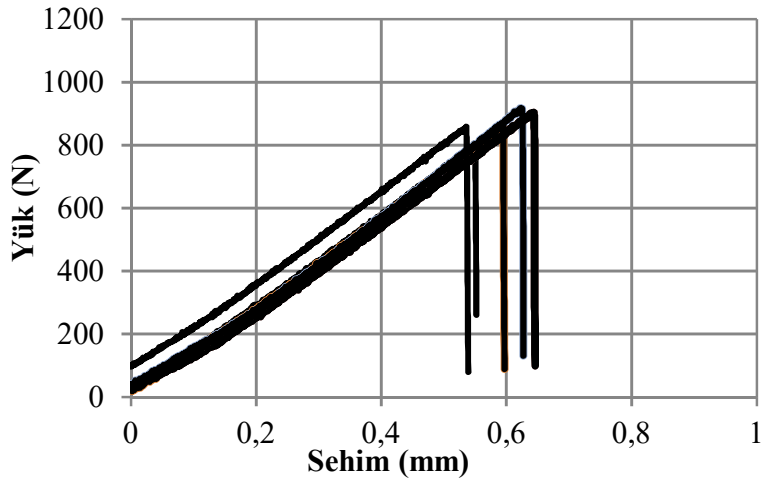

Şekil 9. Referans seramik yük-sehim grafikleri

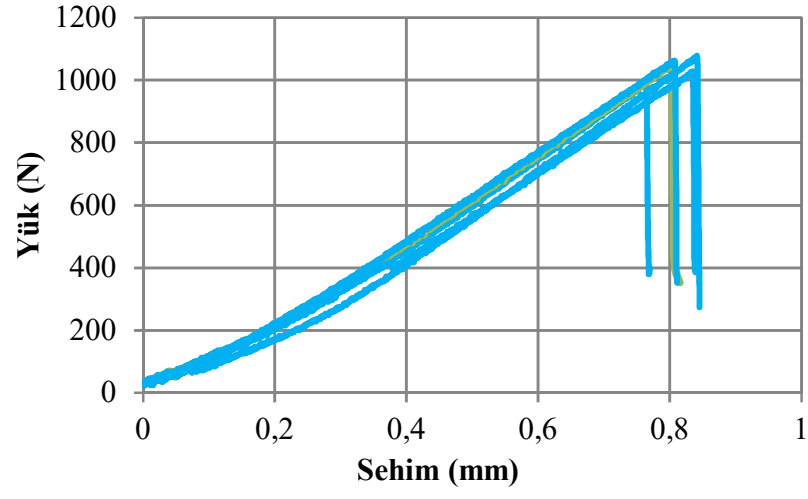

Şekil 10. Cam lifli seramik yük-sehim grafikleri 


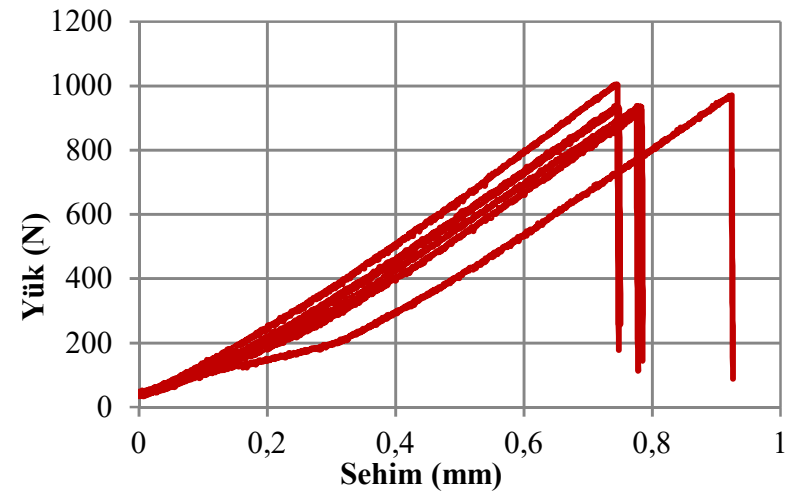

Şekil 11. Fileli seramik yük-sehim grafikleri

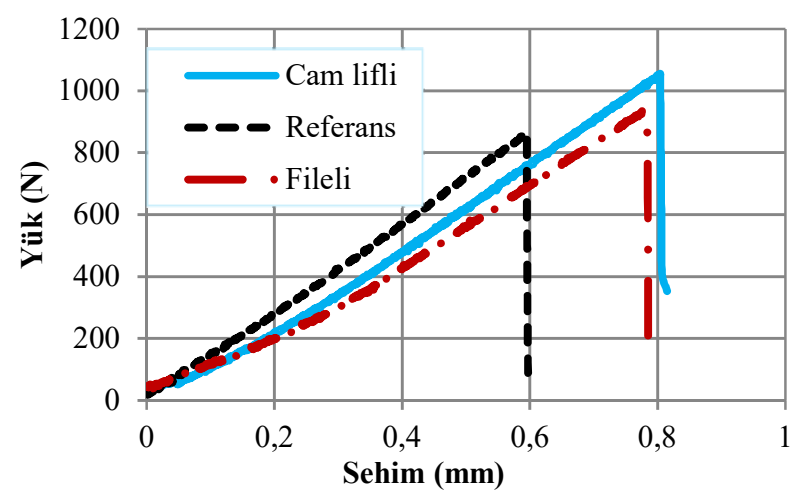

Şekil 12. Seramik yük-sehim grafikleri karşılaştırma

Tablo 4. Seramik eğilme test sonuçları

\begin{tabular}{|c|c|c|c|c|c|c|c|c|}
\hline $\begin{array}{l}\text { Numune } \\
\text { Türü }\end{array}$ & No & $\begin{array}{l}\text { Yük } \\
(\mathrm{N})\end{array}$ & $\begin{array}{c}\text { Eğilme } \\
\text { Dayanımı } \\
\left(\mathrm{N} / \mathrm{mm}^{2}\right) \\
\end{array}$ & $\begin{array}{c}\text { Standart } \\
\text { Sapma } \\
\left(\mathrm{N} / \mathrm{mm}^{2}\right)\end{array}$ & $\begin{array}{c}\text { Ortalama } \\
\text { Eğilme Dayanımı } \\
\left(\mathrm{N} / \mathrm{mm}^{2}\right)\end{array}$ & $\begin{array}{l}\text { Kirılma } \\
\text { Tokluğu } \\
(\mathrm{Nmm})\end{array}$ & $\begin{array}{c}\text { Standart } \\
\text { Sapma } \\
(\mathrm{Nmm})\end{array}$ & $\begin{array}{c}\text { Ortalama } \\
\text { Kirılma Tokluğu } \\
(\mathrm{Nmm})\end{array}$ \\
\hline \multirow{5}{*}{ Referans } & 1 & 857 & 77.13 & \multirow{5}{*}{3.94} & \multirow{5}{*}{78.17} & 457.4 & \multirow{5}{*}{94.77} & \multirow{5}{*}{532.64} \\
\hline & 2 & 804 & 72.36 & & & 440.8 & & \\
\hline & 3 & 864 & 77.76 & & & 514.1 & & \\
\hline & 4 & 915 & 82.35 & & & 671.6 & & \\
\hline & 5 & 903 & 81.27 & & & 579.3 & & \\
\hline \multirow{5}{*}{$\begin{array}{l}\text { Cam } \\
\text { Lifli }\end{array}$} & 1 & 992 & 89.28 & \multirow{5}{*}{2.67} & \multirow{5}{*}{93.53} & 732.6 & \multirow{5}{*}{66.49} & \multirow{5}{*}{845.58} \\
\hline & 2 & 1028 & 92.52 & & & 852.1 & & \\
\hline & 3 & 1060 & 95.40 & & & 892.4 & & \\
\hline & 4 & 1062 & 95.58 & & & 896.9 & & \\
\hline & 5 & 1054 & 94.86 & & & 852.6 & & \\
\hline \multirow{5}{*}{ Fileli } & 1 & 935 & 84.15 & \multirow{5}{*}{3.21} & \multirow{5}{*}{85.63} & 731.3 & \multirow{5}{*}{79.91} & \multirow{5}{*}{756.06} \\
\hline & 2 & 914 & 82.26 & & & 692.3 & & \\
\hline & 3 & 970 & 87.32 & & & 894.4 & & \\
\hline & 4 & 1004 & 90.36 & & & 746.7 & & \\
\hline & 5 & 934 & 84.06 & & & 715.6 & & \\
\hline
\end{tabular}

Numune türüne göre eğilme dayanım ortalamaları ve kırılma tokluk karşılaştırmaları Şekil 13 'de verilmiştir.
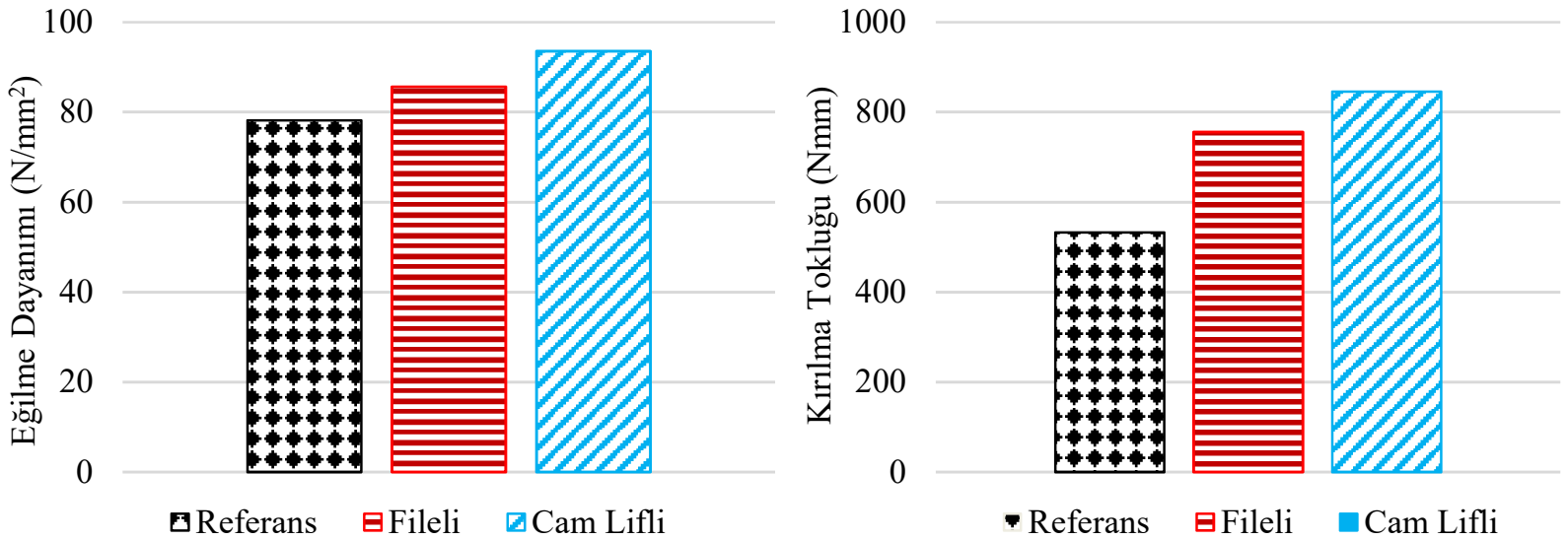

Şekil 13. Seramik eğilme dayanımı ve kırılma tokluğu karşılaştırması 
Seramik numunelerin deney sonuçları incelendiğinde referans numunelerine göre eğilme dayanımları fileli numunelerde \%9.5 ve cam lifli numunelerinde \%19.5 oranında artttı̆ belirlenmiştir. Kırılma tokluğu referans numune sonuçlarına göre fileli seramiklerin $\% 41.8$ ve cam lifli numunelerde ise $\% 58.6$ oranında artış gerçekleşmiştir. Cam lif ile güçlendirilmiş numuneler fitilli güçlendirmeye göre eğilme dayanımında yaklaşık $\% 9$ ve kırılma tokluğunda $\% 11.7$ oranında yüksek performans göstermiştir.

\section{Sonuçlar ve Öneriler}

Mermer ve seramik numunelerin lifli malzemeler güçlendirilmesi konusunda yapılan eğilme testleri neticesinde elde edilen sonuçlar aşağıda özetlenmiştir;

- Farklı lifler ile güçlendirilen mermer numunelerinin deney sonuçlarına göre güçlendirme yapılmamış referans mermerler ile karşılaştırıldığında, fabrikada mermer alt yüzeyine polipropilen file yapıştırılan numuneler \%13.8, laboratuarda epoksi kullanılarak yapıştırılan fileli numunelerde \%22.7 ve cam lif kullanılan mermer numunelerinde ise \%30.8 oranında eğilme dayanımlarının artttığı tespit edilmiştir.

- Mermer numunelerde kırılma tokluğu değerleri referans numnelere göre fabrikada üretilen fileli numunelerde $\% 58$, laboratuarda üretilen fileli numunelerde $\% 62$ ve cam lifli mermer numunelerinde ise $\% 108$ oranında arttığı belirlenmiştir.

- Cam lifli mermerler fabrika fitilli numunelerin eğilme dayanımından $\% 15$, kırılma tokluğu $\% 32$ oranında ve laboratuar fitilli numunelerden ise eğilme dayanımı $\% 6$, kırılma tokluğu $\% 28.4$ oranında artmaktadır.

- Seramik numune testlerinde referans seramiklere göre eğilme dayanımları polipropilen fileli numunelerin $\% 9.5$ ve cam lifli numunelerde $\% 19.5$ oranında artmaktadır. Referans numunelerin kırılma tokluğu değerlerine göre fileli seramiklerin \%41.8 ve cam lifli numunelerin \%58.6 oranında artış gerçekleşmiştir. Cam lifli seramikler fitilli seramiklere göre eğilme dayanımınları $\% 9$ ve kırılma tokluğu $\% 11.7$ oranında artış göstermiştir.

- Tüm numunelerde epoksi kullanılarak file ve cam lifli kumaş yapıştırılırken, güçlendirme malzemelerinin gerdirilerek yapıştırılmasının eğilme performansını artıracağı düşünülmektedir.

- Eğilme testleri sonucunda oluşan gerilmeler neticesinde tüm numunelerde güçlendirme için kullanılan liflerin kopmadığı, seramik yada mermer numunenin tespit edilmiştir. Dolayısıyla lif ve numune ara yüzeyinin geliştirilmesinin malzeme performansını artıracağı düşünülmektedir.

\section{Kaynaklar}

[1] Acar H. Doğal taşlarda çatlak tamir ve gözenek dolgu sistemleri. Türkiye IV. Mermer Sempozyumu (Mersem 2003) 2003; 18-19 Aralık 415-434.

[2] Sarış̧k A. ve Şenturk A. Doğaltaş tamirinde epoxy, polyester, mastik dolgulu ve çimentolu dolguların uygulanma kriterleri. Türkiye IV Mermer Sempozyumu (Mersem 2003) 18-19 Aralık 2003; 553-565. 
[3] Ning Liu, Fang Gang Liu, Guang Jin Li, Man Zhang, He Yi Ge. Jian Jun Wu.. Influence of FRP waste on the properties of unsaturated polyester resin based artificial marble. Materials Science Forum 2015; Vols. 809-810. pp. 264-266.

[4] Jian Jun Wu, Ning Liu, Fang Gang Liu, He Yi Ge, Liang Yu Lv. Influence of FRP residue on the properties of epoxy based artificial granite. Materials Science Forum 2015; Vols. 809810. pp. 248-251.

[5] Zhu Jun, AI De-wu, LI Zhi-chen, LI Guo-rong. Test of bending capacity of marble strengthened with CFRP in varied humidity environment. Journal of PLA University of Science and Technology Natural Science 2001; 2.

[6] Bellinia C., Polinia W., Sorrentinoa L., Turchettaa S. Mechanical performances increasing of natural stones by GFRP sandwich structures. IGF Workshop. Fracture and Structural Integrity Structural Integrity Procedia 2016; 9:179-185.

[7] Erdemli S. Principle of strengthenıng reinforced concrete structures using FRP composite material. Master of Science Dicle University. Graduate School of Natural and Apllied Science June 2012.

[8] Atmaca S. Strengthening of reinforced concrete beams using externally bonded FRP plates. Master of Science. Bogazici University 2001.

[9] Baolin Wan, Cheng Jiang, Yu-Fei Wu. Effect of defects in externally bonded FRP reinforced concrete. Construction and Building Materials 2018;172: 63-76

[10] Mohsen Heshmati, Reza Haghani, Mohammad Al-Emrani, Alann André. On the strength prediction of adhesively bonded FRP-steel joints using cohesive zone modelling. Theoretical and Applied Fracture Mechanics 2018;93: 64-78

[11] Stehn L., Hedman-Petursson E. Resistance and thermal insulation of a composite FRP-steel beam. Thin-Walled Structures 2001; 39:375-394.

[12] Kay-Uwe Schober, Annette M. Harte, Robert Kliger, Robert Jockwer, Qingfeng Xu, Jian-Fei Chen. FRP reinforcement of timber structures Construction and Building Materials 2015; 97: 106-118.

[13] Antonio Borri, Marco Corradi, Andrea Grazin. A method for flexural reinforcement of old wood beams with CFRP materials Composites: Part B 2005; 36:143-153.

[14] Bergner K., Tosch M., Zauer M., Spickenheuer A., Wagenführ A., Heinrich G. Process development for the manufacture of fiber reinforced wood composites (FRWC). Construction and Building Materials 2018; 180:275-284. 